\title{
Conflict Resolution and Management: The Macro Perspective
}

\author{
Moses Onyesom ${ }^{1, ~}$, Emeke Francis Igbesi \\ ${ }^{1}$ Department of Office Technology and Management, Delta State Polytechnic, Ogwashi-Uku, Delta State, Nigeria \\ ${ }^{2}$ Department of Business Administration, Delta State Polytechnic, Ogwashi-Uku, Delta State, Nigeria
}

Email address:

chimosaic@gmail.com (M. Onyesom)

\section{To cite this article:}

Moses Onyesom, Emeke Francis Igbesi. Conflict Resolution and Management: The Macro Perspective. Journal of Investment and Management. Vol. 4, No. 5, 2015, pp. 250-255.doi: 10.11648/j.jim.20150405.25

\begin{abstract}
Conflict is an inevitable phenomenon in this universe as long as humankind exists. This implies that conflict is natural to human nature. However, conflicts usually occur from the pursuit of divergent interests, goals and aspirations by individuals or groups in a defined social or physical environment. Thus, conflict is present when two or more parties perceive that their interests are incompatible, express hostile attitudes, or take, pursue their interests through actions that damage the other parties. Our contemporary world is experiencing varied dimensions of conflicts cutting across religious, tribal, national, racial and socio-cultural inclinations. These macro dimensions of conflicts are open or external expression of dissatisfaction of the aggrieved group which is aimed at injuring other group(s) or reducing if not totally eliminating the existing relationship between the groups. Conflict that has degenerated to macro level becomes difficult and complex for the parties involved to personally resolve their differences alone without the aid of external assistance. Hence, this paper addressed effective styles of conflict resolution and management from the macro perspective.
\end{abstract}

Keywords: Conflict, Macro, Resolution, Interest, Behaviour

\section{Introduction}

Conflicts arise from the pursuit of divergent interests, goals and aspirations by individuals or groups in a defined social and physical environment. According to [1], changes in the social environment such as contestable access to new political positions or perceptions of new resources arising from development in the physical environment are fertile grounds for conflicts involving individuals and groups, who are interested in using the new resources to achieve their goals.

The past ten to fifteen years were characterized by the occurrence of some of the most violent conflicts among several ethnic and religious communities in different regions and states of Nigeria. As in [2] hardly was any region spared some of these conflicts, even though the conflicts differed either in prevalence and intensity, or their protracted or nonprotracted nature. By definition, it implies that conflict is natural to human nature. That is, all humans or groups of humans have goals and interests which may be different with the goals and interests of other groups. This makes conflict inevitable.

Change is a natural phenomenon that produces the major social forces that shape societies. When these changes occur, especially at the middle and micro levels where their effects are individually or personally experienced, they do not happen quickly but are gradual in altering the ecological order, the system of stratification and the social institutions of an entire society causing societies to undergo industrial, political and urban revolution leaving in its wake social problems such as political and economic exclusion of some groups, injustice, poverty, exploitation, diseases, inequality etc.

These conditions places some people or group at an advantage over others and the inability of the social structures in place to bridge this gap and where possible reduce the disparity can cause frustrations and acts of aggression from the disadvantaged individuals or groups. Where these shows of frustration and aggression are ignored and not nipped at the bud, they most often are excuses to violently play out the hostility towards the exploitative group or groups and may escalate to become larger than the small groups or individuals involved to include an entire ethnic groups or organizations.

\section{Overview of Conflict}

Conflict is an inevitable phenomenon in this universe. As 
long as humankind exists, there must be conflict. Conflict has been variously defined by different authors but it is technically seen as an opposition among social entities directed against each other [3]. Similarly, [4] sees conflict as a political process that generates from diversity of choices and distribution of scarce resources in the society.[5]further adds that the occurrence of cheat and aggressive behavior on the part of individuals or groups that lead to the frustration of others may cause conflict. Also [6] states that conflict is the struggle over values or claims to states, power and scarce resources which the aims of the group or individuals involved are not only to obtain the desired values but are to neutralize, injure or eliminate rivals. Thus, conflict is present when two or more parties perceive that their interests are incompatible, express hostile attitudes, or take, pursue their interests through actions that damage the other parties. These parties may be individuals, small or large groups, and countries.

From the foregone, it can be deduced that opposition is the order of contrast to cooperation. Meaning that wherever and whenever cooperation and understanding is lacking opposition sets in. Therefore, conflict can be explained to be an adversarial relationship involving at least two individuals or collective actors over a range or series of issues such as resources control, power, status, values, goals interest etc.

Conflict is a social situation in which at least two parties are involved who strive for goals, making it goal oriented or directed activity designed to improve the position of one party at the expense of the other. It is a perceived state of incompatibility between two or more people or groups and among values where the achievement of one value can be realized only at the expense of the other values. Conflict is an escalated competition between two or more parties each of which aims to gain advantage of some kind and at least one of the parties believes that the conflict is over a set of mutually incompatible goals. Conflicts may or may not be expressed in behaviours. It is one of the energies of life and thus common, natural and unavoidable but its pattern of expression can make or mar any relationship.

\section{Concept of Macro Conflict}

When individuals or groups who had previously been latent over their grievances, oppressions, deprivation, injustices etc suddenly or gradually begin to express these feelings through certain obnoxious behaviours in order to call for attention to their situation which escalates to an entire group, ethnic, state or even national and international, macro conflict has occurred. Macro level conflicts are expression of existing adversary's relationships through aggressive behaviours as a result of unresolved incompatible interest in the social structure of the system or organization.

These lapses in the structural functionalism of a society make it difficult for the rules and status that exists to provide social control or social order which is necessary for survival. Macro conflicts are open or external expression of dissatisfaction of the aggrieved group which is aimed at injuring the other party or reducing it if not totally eliminating the existing relationship between both groups. Conflict that has degenerated to macro level becomes difficult and complex for the parties involved to personally resolve their differences alone without the aid of external assistance. Most times the aggrieved parties may not even be able to state the immediate or direct cause of conflict as they usually lose track of the original causes of grievance. Again, conflicts can escalate to its macro level as a result of the presence of indirect or secondary parties to the conflict. These groups of persons or organizations complicate conflict situations and are difficult to identify because their involvements are by proxy through provisions of war aid and weapons, financial support etc. They are known as "shadow" parties in conflict.

Macro conflicts focus on the broader impacts or effects of conflict or its lack thereof. It considers a wider aspect in conflict such as an entire society, age group or age bracket, population groups, countries, economies, social class etc. Macro conflict goes beyond an individual or organization and conflict at the macro level changes social stratification, economic power and diplomatic stance of a society and thereby its future.

\subsection{Causes of Macro Conflict}

Resources: Conflicts can emerge due to resources. These conflicts arise when two or more groups aspire for the same scarce resources and where the aspiring parties demanding for these resources are more than the available scarce resources. The desire for control of the available scarce resources by a privileged group to the disadvantage of the other aspirants can cause conflicts e.g. the Niger Delta Region crises in Nigeria.

Values: Conflicts may arise due to differences in the value of the people or organization. Values here include philosophy, ideologies, religions etc. The value a group of people or ethnic nationality places on another group may be a constant cause for conflict especially where these values or perceptions are discriminatory and undermines the other group thereby limiting the prospects in certain areas of their lives or hindering their access to certain self actualizing opportunities. Values can bring about oppressive and unequal social structures. e.g Fulani Cattle Herdsmen and some indigent communities in Northern Nigeria, the Igbo cast system.

Oppressive Social Order: Oppressive social order can be a reason for conflicts. Certain social norms are oppressive in nature even though they have always been in existence. This means some people who are by these order placed at advantaged positions can hide behind these orders or norms to do injustice to those at disadvantaged positions and any attempt not to be exploited by the disadvantaged group may cause conflict eruption e.g. violence against women.

Mismanagement of Information: Information is very vital in human and organizational interactions and relationships. Thus any mismanagement of information can generate fatal conflict situations. The average individual's perception of 
things differs from that of an uninformed individual and also affects their reactions on specific issues at a given time. For example, despite the Nigerian government's perception of the relevance of information and establishment of various information gathering and dissemination agencies (e.g public complaints commission, National Orientation Agency, Ministry of information etc.), there still exist major lapses in the effective management of information in Nigeria leading to escalation of issues and eruption of crisis in Nigeria (e.g. the Ogoni Crisis in Rivers State Nigeria and the Political/Religious Crisis in Northern Nigeria).

\subsection{Macro Conflict Management Models/Theories}

The Basic Human Need Theory: Human beings have universal and non negotiable basic needs (that is food, safety, shelter, healthcare, employment, freedom etc.) that must be satisfied. So conflict or violence emerges when these needs are not answered [7]. This theory provides a quiet objective basis for understanding the sources of conflict.

The Marxist Theory: Marx argued that society is structured in main classes. The burgoise (who own the means of production and whose source of income is profit), the land owners (whose income is rent) and the proletariat (who own their labour and sell it for a wage). In these classes, struggle constitutes the engine of change. He noticed that conflict is not a deviant behaviour within the society's structure, the structure itself is a derived factor in the struggle of classes, seen as ownership of property given some persons the power to exclude others [8].

Feminist Perspective of Violence Model: Feminists focus on violence against women, perceiving it as a form of social control that limits or undermines women's ability in all aspects of life. As a result, the occurrence of manifest and latent violence against women is a conflictual situation. Hence, it constitutes a central concern in peace studies. They advocate for the use of feminine values towards the radical transformation of an oppressive social order and consider this as an essential principle in the struggle for achieving peace [9]. For example, violence against women can take different form such as physical violence (beating, corporal, torture etc.), psychological violence (psychological torture etc.), sexual violence (rape, sexual assault, sexual harassment etc.), gender based violence (female genital mutilation, rites of female widow), verbal violence (women based stereotypes or insults) and or economic violence (obstruction of economic opportunities for women etc.).

Environmental Perspective Model: The environmentalists condemn the current misuse or over use of environmental resources and the increasing degradation of the environment due to different factors arguing that such situations could have irreversible and dangerous consequences for the earth and human beings [10]. They also point out that the environment may be a source of conflict, underlining that violent conflict may arise from competition for limited or inequitably distributed resources. For instance, the case of the water scarcity and management conflict in the Nile River Region. The Nile River Water area shared among ten countries namely Burundi, Rwanda, Democratic Republic of Congo, Tanzania, Kenya, Uganda, Ethiopia, Eritrea, Sudan and Egypt. The population within the region is increasing and is expected to double in 25 year, adding to the increasing demand for the water generated by growth in industry and agriculture [11].Scarcity, misuse or inequitable distribution of Nile water is the permanent sources of conflicts in these areas.

\section{Macro Conflict Resolution and Management}

Conflict at the macro level has most often gone beyond the control of the conflicting parties, so even when they see the need for peace, may require the presence and assistance of a third party to initiate the peace move. The third party usually provides neutral ground that are safe enough for peace talk and unbiased opinions for conflicting parties to consider and upon which their decision can be based. Also, warring or conflicting groups may want to enter into peace talks through representative bodies who are expected to, if possible find lasting solution to the existing strives.

Conflict resolution is seen by [10] as a variety of approaches aimed at terminating conflict through the constructive solving of problem while conflict management is defined as the process of reducing the negative and destructive capacity of conflict through a number of measures and by working with and through the parties involved in the conflict. For the purpose of this paper, conflict resolution and management is defined as constructive processes or procedures adopted for solving problems which are aimed at terminating conflicts or reducing its negative and destructive effects by working with and through the conflicting parties.

This means that some conflicts can be permanently resolved when the basic needs of the parties have been met with all necessary satisfiers and their fears allayed and there are non-resolvable conflicts and these can be transformed, regulated or managed e.g. values. Management of conflicts covers the entire handling of conflict positively through its different stages, including efforts made towards prevention by being proactive, conflict limitation, containment and litigation. According to [7], conflict management promotes conditions in which collaborative and values relationships control the behaviour of conflicting parties.

\subsection{Macro Conflict Handling Styles}

Alternative Dispute Resolution (ADR):This looks for and applies non-conventional peaceful methods of settling disputes and resolving conflict situation using the least expensive methods and such ways that satisfy the conflicting parties as well as preserve relationships after a settlement might have been reached. This as an alternative but has special preference for non-violence. The conflict resolution spectrum consists of a range of opinions employable for nonviolent management of conflict which are either voluntary 
processes where the conflict parties have some control over the outcomes of the process and which involves fact finding, in-depth research and case studies, facilitation, negotiation, conciliation, mediation and brokerage or the involuntary processes where the outcomes of the process are outside the control of the conflict parties. Here, the third parties who broker the process hand down outcomes which the parties have to accept either in law or in principle. These involve arbitration, adjudication and law enforcement using the coercive apparatus of state (e.g. warrants \& court orders).

Collaboration: The collaboration process is one in which parties work together on their own to resolve problems through constructive dialogue or other activities such as joint projects, shared utilities etc. Collaboration helps to build trust confidence and mutual respect between groups or nations. When potential or actual conflict parties work together on a number of common issues, projects or themes, it intensifies communication and activities between them. This method is likely to build more mutual respect as well as maintain friendly relations. It is expected that those collaborating are enjoying the relationship and that cooperation in one area can ultimately lead to collaboration in other areas creating a chain of collaborative activities that supports peace building. This method is within the reach of the conflict parties and so, does not involve a third party.

Negotiation: Negotiation is a direct process of structured dialogue and discussion taking place between at least two parties who are faced with a conflict situation [12]. In negotiation, both parties have come to the realization that they have a problem and are aware that by talking to each other can find a solution to the problem. Communication is usually critical to the negotiation process as it can take place only when there is communication between conflict parties and is harder when conflict has escalated and communication is threatened or has altogether stopped. Negotiations are engaged in at the early stages of conflict and are either positional or collaborative in nature. Positional negotiations are aggressive, adversarial and competitive in nature. Parties make inconsiderate demands and perceive themselves to be in competition desiring to win rather than working towards a mutually beneficial outcome. Positional negotiation breaks down easily. Collaborative negotiation are processes where parties educate each other on their needs and concerns and each group seeks for the best ways to solve their problems in ways that the interest and fears of both or all parties are met. The emphasis of collaborative negotiation is on mutual understanding and feeling. All aimed at building a sustainable relationship.

Conciliation: Conciliation is a third party activity which covers intermediary efforts aimed at persuading the parties to a conflict to work towards a peaceful solution. Conciliation involves facilitation. The conciliator communicates separately with the parties and provides the assistance needed from a neutral third party. The aim of conciliation is to reduce tension between parties and in a conflict situation. Conciliation through its many intertwined activities provides a vital background that supports higher activities in conflict resolution and management like mediation [13].

Mediation: Mediation is the process of voluntary intervention undertaken by an external party (third party) that fosters the settlement of differences between parties who retain control over the outcome but which may involve positive and negative inducements. Mediation is usually assisted by a third party where the parties to a conflict admit that they have a problem which they are both committed to solving but in which the mediator manages a negotiation process but does not impose a solution on the parties.

Mediation involves dialogue but requires the presence of a third party. The role of the mediator is to create the enabling environment for the parties to carry out dialogue sessions leading to the resolution of a pending conflict. The mediator helps parties to identify and arrive at common grounds with a view to overcoming their fears and satisfying their real needs. The mediator must have the confidence of the parties to the conflict and refrain from reaching or providing any decisions no matter the weight of the evidence gathered in the mediation process.

Arbitration: Arbitration is the use and assistance of a neutral third party in conflict, who hears the evidence from both parties and thereafter renders a decision which is expected to be binding on both parties called "an award". It is a type of third party intervention for parties to a conflict who select non-violent method of settling dispute. The decisions of the arbitrator are binding but there is a desire to ensure that the outcome in any arbitration process is a fair one.

Adjudication: Adjudication is a non-violent method of conflict management that involves the use of the courts and litigation processes. Parties to disputes may choose to take their case to a court of law before a judge of competent jurisdiction with a legal counsel to represent them. At the end of the adjudication process the court gives a judgment which is legally binding on both parties. The judgment will further be enforced where necessary, by the law enforcement agencies of the state. Adjudication is expected to be a peaceful means of resolving conflicts and disputes. However, its peace is only relative as it tends to destroy trust, love, respect and other forms of confidence between parties but increases suspicion and bitterness of the litigation process for a long time after judgment is given. It usually ends in a winlose outcomes where the winner takes all leaving the loser with nothing. It is expensive and usually takes long to dispose and is outside the control of the conflicting parties who cannot decide how long they take and cannot choose the nature of the outcomes.

\subsection{Crisis Management}

A crisis is an extreme situation in conflict which has reached a point where critical decisions have to be taken to avoid the escalation of conflict to a print of extreme violence. Crisis is sometimes a degenerated state of conflict which threatens human security, intense violence characterized by fighting, death, injury, large-scale displacement of populations etc. When crisis occurs, it becomes the 
responsibility of the government to de-escalate the situation and brings cessation to violence through various means including the use of coercive state apparatus where necessary. Crisis management is usually left to government because when crisis in conflict occurs it threatens and often disrupts communication which can only be restored when normalcy returns. In maintaining crisis situations, many ugly things happen which sometimes consume the state and lead to the collapse of the state as governments are often unable to end the crisis situation resulting in the escalation of violence marked by atrocities and crimes committed against humanity. Also, crisis management can be a statement to the effect that there had been a breakdown of law and order and in which case necessary agencies of law and order are used to contain and where possible restore the situation. These include the police and members of the armed forces. The introduction of the police and other law enforcement agencies may call for the use of extraordinary measures such as force, to restore law and order and may be human rights violations of various descriptions as a result of high-handedness, excess and unprofessional conduct in these exercises. When this happens, the conflicting parties totally lose control of the situation making resolution through non-violent means impossible until normalcy has been restored.

Multi-Track Approach: [11] introduced a multi-track diplomacy systems approach to peace. According to them, there are nine tracks of conceptual and practical framework that assist and work in the peace building sector. This approach emphasizes that there are different parties and stakeholders involved with conflict management and transformation. It goes beyond the traditional believe that the government of a state is the sole machinery of bringing about peace as these governments have most times been unresponsive and are sometimes discovered to be a part of the problem rather than the solution.

Hence, it is important to identify, enlist and provoke the other actors to play their roles in peace building. [11]summarized the nine tracks of peace making activities using the internal level of analysis to include:

(a) Government: Government is involved in peace making through formal processes and institutions of government such as in official diplomacy, policy making, peace building activities and crisis management as well as maintenance of law and order.

(b) Nongovernmental/Professional Conflict Resolution: This relates to conflict management by professional or non-governmental organizations whose activities are in the areas of analysis, prevention, resolution and management of conflict. This includes the civil society groups.

(c) Business or Commerce: Business can make an enormous contribution to peace making in potential and actual forms as it provides economic and commercial opportunities which prevents conflicts. It helps in building both local and international friendship and understanding and opens informal channels of communication and other ways of supporting peace building activities.

(d) Private Citizen and Personal Involvement: Individual citizens can be involved in peace building and development activities through citizens' diplomacy exchange programmes, private voluntary organization, non-governmental organization and other peacemaking activities e.g. local "Vigilante" groups.

(e) Research, Training and Education: This track covers three areas of research as it connects to educational institutions and specialized institutes, think tanks and special research centers including training programmes in conflict and peace as well as specialized skills of negotiation, mediation and general conflict transformation.

(f) Activism or Advocacy: This track covers practices and activities in active non-violence, peace and environmental activism, human rights protection and peace, campaign against proliferation of small arms and light weapons, social and economic justice and protests against governmental policies that threaten peace. For example, "Bring back our girls campaign" in Nigeria

(g) Religion: This track deals with beliefs and peaceoriented actions of spiritual and religious communities such as pacifism, humanism, non-violence, brotherliness as preached by dominant religions.

(h) Funding: The funding of communities is a silent but important sector in peacemaking activities. Many foundations exist, mostly in the developed countries that provide resources to governmental and private groups that are engaged in peace building activities.

(i) Communications and the media: The media and all the channels for the dissemination of information are the aggregate of public opinion and the voice of the people. The media such as print, electronic, video, film etc can promote peace if it chooses to do so and viceversa.

\section{Conclusion}

Conflicts are natural phenomenon in human society. Depending on their intensity, conflicts are expressed sometimes in violent or non-violent ways. They are social situations in which at least two parties with incompatible goals strive to achieve these goals at the expense of each other. Conflicts occur at all levels of human interaction. Macro conflicts focus on the broader impacts of conflict on entire groups or social strata. The causes of conflict are varied and includes resources, values, oppressive social order, mismanagement of information etc. and these could be permanently resolved but where this is impossible will be managed through collaboration, alternative dispute desolation (ADR), negotiation, conciliation, mediation, arbitration, adjudication, crisis management and multi-track approach methods. Conflict is an inevitable occurrence in every human existence, at all levels and takes different forms which could be either violent or non-violent ways. At the 
macro level, conflicts situations affect entire social order and groups or even countries. Conflicts arise as a result of a number of issues and could either be resolved or managed in a number of ways using appropriate methods in consideration of the causes of conflict.

\section{References}

[1] O. Otite, Aspects of conflicts in theory and practice in Nigeria. Ibadan: Spectrum Books limited, 2001.

[2] T. V. Best, Philosophical analysis of conflict. Aldershort: Ashgate, 2004.

[3] I. O. Albert, Introduction to third party intervention in community conflicts. Ibadan: John Archers Pubs. Ltd, 2001.

[4] A. Ball, Modern politics and government. London: McMillan Press Ltd, 1983.

[5] R. Stagner, The psychology of human conflict. Ibadan: Spectrum Books Ltd, 1995.

[6] A. P. Schmid, Thesaurus and glossary of early warnings and early responses in Introduction to peace studies. National
Open University of Nigeria Study Module. Lagos. Canal paper Converters Ltd, 2000.

[7] J. Burton, Conflict resolution and prevention. London: MacMillan, 1993.

[8] R. Runmel, Understanding conflict and war: Conflict in perspectives. Retrieved from www.hawaii.edu/powerkills/CIP.CHAP3.HTM, 1997.

[9] H. Jeongh-Won, Peace and conflict studies: An introduction. Burlington: Ashgate Pub. Ltd, 2000.

[10] C. A. Miller, A glossary of terms and concepts in peace and conflict studies. Geneva: University for peace, 2003.

[11] L. Diamond, and J. MacDonald, Multi track diplomacy: A systems approach to peace. Connecticut: Kumarian Press Inc, 1996.

[12] E. Nnabuife, Organisational behavior and management theories. Nimo: Rex Charles and Patricks Publications, 2009.

[13] V. B. E. Abia, Contemporary issues in international relations. Lagos: Concepts Publishers Ltd, 2000. 